\title{
O Breve Compêndio da Arte Scenica ou Arte de Declamar e a vulgarização de uma ciência de palco
}

\author{
GUILHERME FILIPE
}

In the absence of a tradition of technical-artistic literature in Portugal in the nineteenth century, the writing of a booklet on acting and staging by Francisco Ângelo da Silva Veloso, a stage manager at the Teatro de D. Fernando and Rua dos Condes, represents an important moment in the History of Theatre. Not only it gives an inside view of backstage, but it also brings forward the importance of acting technique, to develop the quality of performance and the social status of actors. This article reviews the Breve Compêndio da Arte Cénica, seeking to fit it in its time, as the first technical work aimed at a wide audience of professionals and theater spectators and, ultimately, amateurs in the private drama groups of the societies that the politics of Regeneration promoted.

THEATRE HISTORY / THEATRE STUDIES / 19TH CENTURY / STAGE THEORY / ACTING

Quando escreve o prefácio à terceira edição de Catão (1839), Garrett afirma perentório, em relação ao exercício da escrita dramática, que o problema da produção não residia na «mingua de talento», mas no «mau methodo, [no] principio errado com que [os dramaturgos] trabalhavam» (1904: I, 524). Um conceito que englobava os atores, os empresários e, em última análise, os espectadores, habituados ao mau-gosto das representações enfáticas de pendor melodramático. O programa garrettiano de modernização do gosto do público pela representação cénica cumpriu-se com «precisão matemática», mas, na realidade, o que ficou foi, sobretudo, um «rastro de entusiasmo pelo teatro», não se conseguindo eliminar essa «predilecção para o sensacional e o emocional» (Crabée-Rocha, 1954:231). Seguido mais como escola, e menos como doutrina, o modelo proposto produziu de forma fecunda êxitos de bilheteira, que a crítica elogiou em função de elementos estranhos à arte e à literatura» (idem: 234). 
Garrett provocou uma revolução literária como reflexo da revolução social que viveu. Segundo Gomes de Amorim, a sua reforma do teatro foi a expressão da sua ideia de revolução cultural, ou seja, a de uma «indissoluvel alliança» entre política, literatura e artes, que tornaria possível o progresso civilizacional (Amorim, 1881-1884: III, 66). O palco permitia trazer para a esfera pública a controvérsia que a tertúlia privada dos árcades setecentistas privilegiara, e a tragédia de modelo clássico, cedendo inevitavelmente lugar ao drama, fazia surgir a nova forma, «filha do novo estado social», que trouxe consigo a exigência do estudo da vida no mundo (Silva, 1848a: 121). Américo Lindeza Diogo e Osvaldo Silvestre subscrevem a mesma ideia: «É na pessoa de Garrett, e no seu percurso de homem de letras (i.e., na sua obra), que notamos o esforço literário mais consequente de renovação relativamente apressada daquela classe dos salões rumo a um mais geral público burguês» (1996: 89).

Porque uma nação sem teatro seria «um paiz órfão de artes e vazio de cultura» (Silva, 1848b: 234), Garrett idealizou um modelo harmónico para a vivência do fenómeno teatral. Produção dramática, realização plástica e receção estética materializam os três momentos cruciais dessa realidade espetacular. A sua experiência pessoal, enquanto ator amador, ensaiador, dramaturgo e crítico dramático-teatral, intersecionando as belas-letras e as belas-artes, clarificou a sua estratégia global: a criação de uma literatura dramática moderna e a formação de atores de qualidade, que a representassem, estariam na base da educação e ilustração do espectador.

Demonstrou a geração romântica que o drama era a vida revelada pela arte: seus limites, o próprio mundo, cujo espetáculo descrevia. Sendo uma forma essencialmente popular, fez do Homem o seu tipo eletivo. Inspirando-se na verdade e na natureza, o drama abordou o infinito moral das paixões, e delegou no ator, enquanto veículo do poeta, a capacidade de se transfigurar em poeta da cena que habitava. Todavia, «a sorte do poeta e a do actor nunca foram eguaes»; enquanto naquele se estimava o talento inspirado, neste, de «sensibilidade estremecida e caprichosa», estimava-se o talento que «só [amadureceria] ao sol do triumpho, no meio do aplauso e da esperança» (idem: 235).

Garrett percebeu a necessidade e a dificuldade da formação do espectador, e, por isso, lutou contra as «chronicas velhas», e o «Elucidário de Viterbo» na produção dramática, contra a «sem-cerimonia» criadora de «arqueologia fantástica» na representação plástica da cena, e contra as «estatuas gothicas, toscas como a rusticidade da esculptura do tempo 
que symbolisavam» na realização estética interpretativa (Ferreira, 1872: I, 162).

O ideal romântico de educação popular traduzia o desejo libertário de formar o cidadão livre e uma opinião pública consciente. L'étude fait l'avenir $^{1}$ :

Não pode haver ilustração geral e proveitosa sem que as grandes massas de cidadãos [...] possuam os elementos científicos e técnicos indispensáveis aos usos da vida do estado atual das sociedades. ${ }^{2}$

A partir de 1850, a Regeneração veio desenvolver esse espírito primordial, promovendo o ensino técnico e profissional, e procedendo à estruturação legal da atividade teatral no território nacional. Ainda que se tratasse de «uma ação moral», o teatro era também um «agente comercial», e nessas duas «relações» o equacionava o redator do jornal crítico-literário Galeria Theatral. Não eram apenas a declamação, a música e a dança que sustentavam o teatro. «Para que elas [brilhassem] aos olhos do público, quantas outras [artes acessórias] não [seriam] necessárias»:

O publico de hoje não quer só que Ihe falem ao espirito, deseja também que Ihe falem aos olhos; e por isso o teatro tem necessidade de alimentar muitas mais artes, do que d'antes. [...] O teatro considerado como agente comercial sustenta muita industria, e alimenta milhares de indivíduos. ${ }^{3}$

Ao contrário da cultura francesa, inglesa ou germânica, que foram produzindo literatura técnico-artística sobre teoria dramática, em Portugal escasseava esse tipo de obras ${ }^{4}$, como já havia motejado José Agostinho de Macedo, nas Pateadas:

A grande Republica das letras, com especialidade nesta Colonia, que se chama Lusitania, está falta, ou balda de livros elementares sobre certas artes, e Sciencias, e parece, que tanto mais importantes são estas Sciencias,

1 Lema do Colégio Escola Académica, fundada, em Lisboa, em 1847.

2 Preâmbulo ao Decreto da Secretaria de Estado dos Negócios do Reino sobre «Instrucção Secundária», de 17 de novembro de 1836, Diário de Lisboa, 2. ${ }^{\circ}$ semestre, pp. 136-39.

3 Galeria Theatral, n. ${ }^{\circ} 1,21$ de outubro de 1849 , pp. 1 e 2.

4 Em 1800, o pastor sueco Carl Israel Ruders recenseou de forma pouco abonatória a Dissertação histórica e crítica sobre as representações teatrais (1799), de Francisco Lourenço Roussado (F. L. R.), obra sem merecimento e de pretensiosismo faccioso (Ruders, 2002: I, 98-100). 
tanto mais sensível he a falta dos Livros elementares. Eu julgo que não he menos importante a Sciencia de abreviar os dias da vida, que a Sciencia das Pateadas de Theatro. (Macedo, 1825: 11)

Sobre a utilização de manuais didáticos destinados ao ensino da Escola de Arte Dramática, surgem referências memorialistas e bibliográficas avulsas. $\mathrm{O}$ facto de não terem sido ainda encontrados indicia a possibilidade de circulação em versões manuscritas, não impressas (Vasques, 2012: 153). Numa primeira fase, referenciam-se os compêndios de César Perini de Lucca, de João Nepomuceno de Seixas, e os Apontamentos sobre declamação, de Duarte de Sá, recenseados por Luís da Costa Pereira, nos seus Rudimentos da Arte Dramática (1890) e citados em bibliografias sobre técnica teatral, em vários autores do início do século $\mathrm{xx}$, e atualmente perdidos.

A formação profissional dos atores, na primeira metade de Oitocentos, apresenta insuficiências teóricas, e é sustentada sobretudo pela transmissão de testemunho geracional através da prática de palco, sob a direção de ensaiadores de qualidade variável. Note-se que os ensaiadores dos teatros do Salitre, da Rua dos Condes, ou do Ginásio, foram também inspiradores das práticas das sociedades de curiosos-dramáticos lisbonenses. Por outro lado, o registo memorialista de alguns atores refere as obras estrangeiras, que ainda se estudavam, na segunda metade do século: uma trilogia composta pelo Paradoxe sur le comédien (1773), de Diderot, por L’Art Théâtral (1863-1865), de Joseph-Isidore Samson, e pela romântica Théorie de l'art du comédien ou Manuel théatral (1826), de Aristippe, na nova edição dos Manuais Roret (1854). A evolução trouxe a consciência de que não bastava assimilar os «conselhos úteis», sem que houvesse uma correção prática sistematizada da informação teórica (Rosa, 1915:39, 40).

Contudo, a reflexão teórica sobre a Arte Dramática perpassa avulsa pelo espaço da imprensa escrita - recensões críticas, folhetim-teatro, ou a crítica teatral-, pelo espaço referencial introdutório (prefácio, exórdio, proémio ou prolegómenos), ou conclusivo (posfácio), das edições de obras dramáticas impressas, mas também em algumas obras de intuito sistematizador. E, mais uma vez, se regista a existência de uma obra perdida, o opúsculo de Rodrigo de Azevedo Sousa da Câmara, Reflexões sobre a Arte-Dramática (1842), apenas referenciadonas Memórias do Conservatório Real de Lisboa ${ }^{5}$ no Breve Compêndio da Arte Scenica ou Arte de Declamar. 
O desaparecido folheto de Sousa Câmara dividia-se em duas partes, tratando da «composição do drama» e da «representação em scena», e procurava prestar um «serviço aos comediantes», dando a conhecer «algumas das regras geraes até então ignoradas» (Veloso, 1856: 56).

O mesmo intuito se encontra presente no Breve Compêndio da Arte Scenica ou Arte de Declamar (1856), que corresponde à primeira obra de carácter técnico-artístico redigida por um profissional de teatro, razão pela qual merece a nossa atenção. Trata-se de um manual de bolso diminuto opúsculo de 85 páginas e apenas 11 centímetros -, cujo autor, Francisco Ângelo da Silva Veloso, dedica ao «digníssimo» presidente da edilidade lisboeta, Manoel Salustiano Damasceno Monteiro ${ }^{6}$, e oferece «aquelles que se dedicão» à arte teatral e carecem de um Breve Compêndio, que os guie nesse espinhoso caminho. $\mathrm{Na}$ «Dedicatória», com a modéstia que a retórica exige, o autor almeja que este «fructo d'algumas horas de trabalho» seja, «se não sublime, ao menos claro, e inteligível» (Veloso, 1856: 5). À míngua de talento próprio, reconhece que apenas a força de vontade lhe «fez lançar ao papel essas frases mal co-ordenadas [...], esta lucubração» (idem: 6, 7), indiscutivelmente elogiada pelo ator Vale, ao encarregar-se do «Prólogo» ao «compêndio»:

Limitado e simples, nas mãos dos artistas, um artista depõe o seu compendio. Desejoso de auxiliar os principiantes, na difícil arte da declamação, elle vai, sem duvida, desafiar o critério; mas é n'isso mesmo que se bazêa a gloria; os poucos escriptos que sobre este assumpto teem aparecido, fizeram crêr ao auctor, que o seu livro serviria, se não de guia aos comediantes, ao menos de incentivo à judiciosa critica dos sublimados talentos, que jazem como adormecidos. Esperançado está pois o auctor no apparecimento d'um compendio, que suplantando o seu, faça encaminhar o principiante no actrissismo, pela estrada real do aperfeiçoamento; por isso não duvida de que lhe será taxada a sua ousadia como um serviço prestado à sua pátria; o auctor é pobre, deu o que tinha, nada mais podia dar. (Veloso, 1856: 8, 9)

O discurso do prestigiado ator legitima a «ousadia» autoral de Silva Veloso, «criador e instituidor da associação teatral da rua dos Condes e

6 Damasceno Monteiro foi vereador eleito desde 1852, tendo ascendido a presidente em 1854, e mantendo-se até 1858. Por altura do seu falecimento, o obituário do Jornal do Comércio (15 de junho de 1890) fez referência à sua formatura em medicina, à sua condição abastada e às boas relações que mantinha com o Partido Regenerador (Correia, 2009: 3). 
contrarregra no teatro de D. Fernando» (Veloso, 1856: frontispício), evidenciando-lhe a qualidade de «desafiar» a norma vigente, sustentada por algumas inominadas obras sobre a matéria - porventura Aristippe ou Le Brun, mais certo Diderot -, mas, sobretudo, atribuindo-lhe o galardão de «serviço prestado à pátria», pela sua apologia do «actrissismo» (interessante neologismo para definir o mundo diáfano da atuação!).

No prefácio «ao leitor», Silva Veloso lamenta que razões financeiras tivessem coartado a edição de O Ensaiador Moderno, título inicialmente pensado para uma sua coleção de «figurinos antigos e modernos de diversas classes da sociedade, e differentes povos, que [servissem] como guia aos comediantes, assim como o desenho de attitudes demonstrativas das paixões mais fortes» (Veloso, 1856: 10), e que antecederia o estudo dos «deveres e atribuições, no desempenho de tão importantes logares» (idem: 11) de Ensaiador e de Contrarregra no teatro de declamação, que deveriam ser ocupados por «indivíduos hábeis, mas não comediantes» (idem: 13).

Segundo Veloso, a maioria dos comediantes não apresentava o «dom perscrutador e vigilante» próprio do hábil ensaiador, que lhe permitia «ensaiar toda e qualquer peça dramática», sem que estivesse obrigado a «desempenhar cabalmente» as indicações necessárias ao bom desempenho do papel por parte do actor (idem: 22, 23). Na defesa da autonomia do cargo de ensaiador, o Breve Compêndio desenvolve uma espécie de teoria de incompatibilidade de funções; na «cadeira do ensaiador» não deveria sentar-se um indivíduo da «classe dos comediantes», os «principaes chefes do monopólio», porque «o Ensaiador comediante, ou hade ensinar, ou emendar-se a si próprio, de defeitos que não pode descortinar e que nenhum dos seus inferiores, ainda que lh'os reconheça ouzaram notar-lhe» (idem: 29, 30). A ética defendida por Silva Veloso sustenta-se pela forma como define as qualidades próprias às duas profissões: a perspetiva abrangente do olhar sintético do ensaiador e a perspetiva particular do olhar analítico do intérprete.

Eis um argumento que legitima o papel do ensaiador, como pedagogo de atores, que faça «caminhar os seus discípulos com mais rapidez para a grande perfeição que a arte requer» (idem: 51), sobretudo, num momento em que a Escola de Declamação do Conservatório Real de Lisboa não se encontrava funcionando nas melhores condições: 
dirigia, do que lhes provinha o seu desenvolvimento, iam para outro onde havia um Ensaiador de menos capacidade que Ihes fazia perder todas as ventagens adquiridas com o precedente; lamento nimiamente o haverem-se perdido inteligências, que bem dirigidas e auxiliadas não só fariam um dia a glória e engrandecimento do seu paiz. Eu quizera que assim como se tem trabalhado no aperfeiçoamento de todas as artes, a dramática merecesse igual solicitude, não permitindo os governos que empresa alguma confiasse a direcção do palco de qualquer teatro, a indivíduos que não tivessem as necessária habilitações. (Veloso, 1856: 53, 54)

São estas as premissas que movem Silva Veloso na necessidade de redigir o Breve Compêndio da Arte Cénica ou Arte Dramática, como modo «fácil de estabelecer um systema, pelo qual se aclare o estudo d'esta arte» (idem: 54, 55), na esperança de que tal motive o aparecimento de outras obras sobre o assunto, com mais «elevado mérito» (idem: 55 ).

Eugénia Vasques, sustentada em fontes da época, refere as tentativas precoces (ainda na década de 1930) para corrigir a situação de impreparação dos actores e de ineficácia dos ensaiadores, mostrando a ligação estreita entre ambos - actores e ensaiadores - na transformação lenta da qualidade artística do teatro que se mostrava nos palcos portugueses. A introdução do jogo naturalista na prática teatral oitocentista é disso exemplo, ao revelar a necessidade de conjugar a preparação do actor e a sua direcção pelo ensaiador, possuidor de uma visão geral do espectáculo (2010: 17-25).

O Compêndio, propriamente dito, segue o tradicional modelo didático em forma de diálogo, numa espécie de derradeiro exame oral a um candidato ao «actrissismo»:

- Que entendeis vós que seja a arte de declamação, ou arte cénica?

- Entendo aquella que nos ensina a representar com naturalidade, qualquer papel de que formos encarregados. (Veloso, 1856: 58)

Silva Veloso objetiva desde logo o conceito fundamental do naturalismo e da naturalidade em cena: ao ator compete expressar adequadamente o sentimento idealizado pelo dramaturgo, através do gesto - fisionómico, entenda-se-, da gesticulação, transmitindo assim as «diferentes paixões por que o homem é dominado», vestido e caracterizado «apropriadamente e com a maior semelhança possível» (idem: 59). O estudo assíduo do papel, pela sua leitura exaustiva até à memorização, 
complementar-se-ia com a frequência dos ensaios e o estudo do meio, para conseguir a «maior verosimilhança possível» (idem: 60). Não deixa de ser interessante que Silva Veloso utilize, num curto espaço textual, os termos «semelhança» e «verosimilhança», e que muito apropriadamente faça a distinção entre a imagem exterior credível e o retrato psicológico comportamental do papel, sustentado pela verdade de atuação, fundamentada na investigação histórica («história da nação a que o personagem pertence»), sociológica («discorrer pelos actos de sua via o caracter de que era revestido») e patológica («se for defeituosa na sua construção física»):

O comediante não pode chegar ao grau de perfeição, em quanto não fôr um fiel imitador, nem pode vir a ser um verdadeiro artista, se faltar a qualquer circumstancia, que deixe de iludir o espectador, que espera n'elle ver o personagem que muitas vezes conheceu, ou tem délle as mais exactas informações. (Veloso, 1856: 61)

Apesar disto, a teoria de Silva Veloso continua escorada no poder ilusório, conferido tanto pelo guarda-roupa como pela caracterização, que sustentariam, na ausência das características naturais do ator, o efeito convincente do retrato. Seguindo as tradicionais teorias sobre a expressão fisionómica, dever-se-ia recorrer ao trabalho dos retratistas, ou, pelo menos, a coleções de «estampas apropriadas», para estudo da obtenção da semelhança física.

O exame do «discípulo» torna-se agora mais técnico, incidindo sobre as características da caixa do teatro, a explicação da estrutura física da sala de teatro e da perspectiva do olhar do espectador, os espaços destinados aos atores e sua função, a nomenclatura das partes fundamentais que qualquer ator deveria conhecer, a bem do seu desenvolvimento artístico. Por fim, como corolário do reconhecimento dos atributos necessários para «chegar a ser um bom comediante» (idem: 79), Silva Veloso remata o seu manual de bolso com duas respostas que definem o seu ponto de vista. Enquanto pessoa, o comediante deveria «saber ler, ter intelligencia mais do que medíocre», não sofrer de doença evidente, possuir boas características vocais e versatilidade histriónica, e ser estudioso. Socialmente deveria ter «bom comportamento moral e civil», ser humilde e ter «presença de espírito» (idem: 80). Um modelo de pessoa, para um modelo de ator, porque ao subir à cena outros «quesitos» se lhe exigiam, entre os destinados ao exercício da profissão e os referentes ao seu estatuto social: 
Muitos mais se requerem, porém esses podem-se ir adquirindo com o estudo, e devem-se procurar; pois sem eles não se pode alcançar a reputação na arte de declamar, saber compreender o que lê para conhecer o sentido em que o poeta dramático escreveu, saber dar à sua voz as entoações conducentes, saber empregar o gesto tão necessário, quando bem aplicado, devendo procurar ter algumas noções de música, saber escutar-se para se corrigir, ter conhecimentos históricos, se não especiaes ao menos geraes, evitar o ser exaggerado na declamação e nos gestos, ter bom gosto na escolha dos typos, esquivando-se a copiar aquelles que possam tomar a imitação por ultraje à sua pessoa, fazer com que pela sua conducta e reputação possa ser admitido na boa sociedade, onde melhor aprenderá a cortesia e maneiras de sala, indispensáveis na alta comédia, e possa conhecer do tratamento usado entre as altas personagens, constituir-se fiel observador em todas as classes da sociedade, a que deve procurar chegar, para conhecer os seus usos e costumes particulares, e características, aprender alguma coisa dos idiomas, francês, inglez e hespanhol, saber ao menos um pouco de música, dança e jogo de armas, etc., etc. (Veloso, 1856: 81)

Como corolário de legitimação do papel social do ator, Silva Veloso defende que a qualidade da formação profissional credibilizaria a sua função social, enquanto representante de uma «arte nobre por natureza, pois contribui para a ilustração do povo» (idem: 82), fruto de «ilustração do século, que faz reconhecer o teatro como um dos melhores passatempos de um povo civilizado» (idem: 83). O papel da arte teatral ganhava assim um estatuto favorecido na relação com o público e o contexto cultural coevo, como muito bem explanou Mário Vieira de Carvalho (1993) no estudo que dedicou ao Teatro Nacional de São Carlos e à transformação do lugar dos teatros na correlata modificação da esfera pública e sua caracterização sociocomunicativa burguesa.

Conscientes de que a encenação transportava para o espaço cénico uma realidade fictícia, criando-lhe uma existência concreta, os «teorizadores» da arte teatral, no segundo quartel do século XIX, deram continuidade à proposta de Garrett, na formação de públicos e de profissionais de espetáculo e, como novidade, criaram perspectivas metodológicas de trabalho para os estudiosos de teatro, não esquecendo os amadores dramáticos, uma área em franco apogeu, que se prolongou pelo século seguinte. O Breve Compêndio da Arte Scenica ou Arte de Declamar deu assim início a um conjunto de obras destinadas à formação de «fazedores» de teatro, 
além dos dramaturgos. Manuel de Macedo, Augusto de Mello, Luís da Costa Pereira e Augusto Garraio abriram caminho a futuros autores de compêndios de teatro - Sousa Bastos (Carteira do Artista, 1898, Dicionário do Teatro Português, 1908), José António Moniz (Arte de dizer: curso de dicção, 1903, Arte de representar, 1909), António Walgode (O livro do ensaiador, 1915), Eusébio Queirós (O livro do ensaiador, 1915), António Pinheiro (Estética e plástica teatral, 1925), Carlos Santos (Poeira de palco, 1927), A. Vítor Machado (Guia prático de encenação, Guia prático do actor, 192?) - e à divulgação da arte dramático-teatral. A arte de representar, sobretudo no drama íntimo moderno, exigia um apuro estético e o recurso a uma «nitidez de acabamento» (Macedo, 1885: 24), por parte de todos os agentes do fenómeno teatral, para que o espectador pudesse fruir do «efeito de realidade», através da ilusão que o realismo cénico pretendia atingir.

\section{REFERÊNCIAS BIBLIOGRÁFICAS}

AMORIM, Francisco Gomes de (1881-1884), Garrett Memórias biographicas, 3 vols., Lisboa, Imprensa Nacional.

CARVAlho, Mário Vieira (1993), Pensar é morrer. Ou o Teatro Nacional de São Carlos na mudança de sistemas sociocomunicativos desde fins do século XVIII aos nossos dias, Lisboa, Imprensa Nacional-Casa da Moeda.

CORREIA, Rita (2009), «Annaes administrativos e económicos», Lisboa, Câmara Municipal de Lisboa.

CRABÉE-ROCHA, André (1954), O teatro de Garrett, 2. a edição, Coimbra, s/e.

Diogo, Américo Lindeza / SILvestre, Osvaldo (1996), Rumo ao português legítimo, Braga e Coimbra, Angelus Novus.

FERREIRA, José Maria de Andrade (1872), Litteratura, musica e bellas-artes, 2 vols., Lisboa, Typ. J. G. de Sousa Neves.

GARRET T, J. B. S. L de Almeida (1904), Obras completas de Almeida Garrett, prefaciada, revista, coordenada e dirigida por Theophilo Braga, 2 vols., Lisboa, Empresa da História de Portugal/Livraria Moderna.

MACED O, José Agostinho de (1825), Pateadas de Theatro investigadas na sua origem e causas, 2. ${ }^{\mathrm{a}}$ edição, Lisboa, Imp. de João Nunes Esteves.

MACEDo, Manuel (1885), A Arte Dramática, Lisboa, David Corazzi, Biblioteca do Povo e das Escolas, n. 116.

Ros A, Augusto (1915), Memórias da Cena e de Fora da Cena, Lisboa, Livraria Ferreira.

RUDERS, Carl Israel (2002), Viagem em Portugal 1798-1802, reimpressão, tradução de António Feijó, prefácio e notas de Castelo Branco Chaves, Lisboa, Biblioteca Nacional.

SILVA, Luiz Augusto Rebello da (1848a), «Litteratura e Bellas Artes: A Eschola Moderna Litteraria. O Sr. Garrett», A Epocha, v. 1, n. ${ }^{\circ}$ 8, pp. 121-24.

- (1848b), «Litteratura e Bellas Artes: A Eschola Moderna Litteraria. O Sr. Garrett», A Epocha, v. 1, n. ${ }^{\circ} 15$, pp. 234-38.

VASQUes, Eugénia (2010), Para a história da encenação em Portugal, Lisboa, Sá da Costa Editora.

- (2012), A Escola de Teatro do Conservatório (1839-1901). Contributo para uma História do Conservatório de Lisboa, Lisboa, Gradiva.

Veloso, Francisco Ângelo da Silva (1856), Breve Compêndio da Arte Scenica ou Arte de Declamar, Lisboa, Typ. de E. J. da Costa Sanches. 


\section{GUILHERME FILIPE}

Actor/encenador profissional, professor e investigador de teatro (Centro de Estudos de Teatro). Doutorado em Estudos Teatrais (Faculdade de Letras da Universidade de Lisboa), com a tese O Gosto Público Que Sustenta o Teatro: Subsídios para o estudo da vulgarização do pensamento teatral oitocentista em Portugal. 